\title{
Lei de Responsabilidade Fiscal e Implicações na Despesa de Pessoal e de Investimento nos Municípios Mineiros: Um Estudo com Dados em Painel Dinâmico ${ }^{\star}$
}

\author{
- Roberto Santolin * - Frederico Gonzaga Jayme JR. ** \\ - JÚLIO CÉSAR dOS REIS **
}

\begin{abstract}
RESUMO
O presente trabalho realizou um estudo dos possíveis impactos da Lei de Responsabilidade Fiscal (LRF) no comportamento das despesas dos municípios de Minas Gerais. Para tanto, foram analisados cenários anteriores e posteriores da LRF, com base nos quais se comparou o comportamento das prefeituras municipais em relação às suas políticas de gastos. Inicialmente foi identificada uma convergência da despesa com pessoal nos municípios mineiros. Além disso, verificou-se também um processo de convergência dos gastos com investimento com relativa redução do mesmo. A metodologia econométrica baseou-se em painel dinâmico. Este processo esteve associado, por um lado, com a convergência e ampliação dos gastos de pessoal, e por outro, pelas restrições de operações de crédito impostas pela LRF.
\end{abstract}

\section{Palavras-Chave}

lei de responsabilidade fiscal, finanças municipais, painel dinâmico

\section{ABSTRACT}

This paper aims at analyzing the impacts of the Fiscal Responsibility Law (FRL) on total expenditures across municipalities in the State of Minas Gerais, Brazil. To accomplish the objectives of the paper, we analyzed the situation before and after the Law using a dynamic panel. There was convergence on expenditure and investments after the advent of the FRL. There has been identified a tendency for convergence in staff expenses among Minas Gerais' municipalities. Besides, it has also been possible to identify processes of convergence in investments, with relative reduction in its overall value. These have been associated, on the one hand, with convergence and increase in staff expenses; on the other, with restrictions on credit operations imposed by the law.

\section{KEYWORDS}

fiscal responsibility law; municipal finance, dynamic panel

\author{
JEL CLASSIFICATION
}

HII, H5O, H54

\footnotetext{
+ Os autores agradecem à Carlos Eduardo Suprinyak (CEDEPLAR/UFMG), Fabiana Fontes Rocha (FEA/USP) e aos pareceristas pelos comentários e sugestões. Quaisquer erros remanescentes são de inteira responsabilidade dos autores. Os autores também agradecem ao CNPq e a FAPEMIG pelo suporte financeiro.

* Doutorando em Economia pelo CEDEPLAR/UFMG. E-mail: rsantolin@cedeplar.ufmg.br.

** Professor do Departamento de Economia e do CEDEPLAR/UFMG, pesquisador do CNPq. E-mail: gonzaga@ cedeplar.ufmg.br.

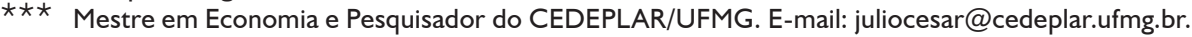

Endereço para contato: Av. Antônio Carlos, 6627 - Faculdade de Ciências Econômicas - Universidade Federal de Minas Gerais - Belo Horizonte - MG. CEP: 31270-901.

(Recebido em junho de 2008. Aceito para publicação em março de 2009).
} 


\section{$1 \quad$ INTRODUÇÃO}

A atual configuração de descentralização fiscal e de atribuições das esferas municipais é caracterizada por um fortalecimento da execução de políticas públicas, como saúde, educação e infraestrutura urbana. As características do atual sistema federativo, moldadas na Constituição de 1988, ampliaram as responsabilidades dos municípios, ao mesmo tempo em que esta não dispôs de fontes para obtenção de recursos que permitiriam a execução de tais políticas. Neste contexto, grande parte das principais fontes de receitas dos municípios de menor porte baseia-se em repasses de transferências de arrecadações tributárias do respectivo Estado e do governo federal.

Neste ambiente institucional, dois fatos merecem atenção. O primeiro refere-se à Lei de Responsabilidade Fiscal (LRF), promulgada em 4 de maio de 2000, cujo objetivo é o maior controle dos gastos públicos e transparência na gestão fiscal. A LRF, concebida como uma legislação abrangente sobre Finanças Públicas que incide sobre todas as esferas de governo, ratifica o processo de controle de gastos, bem como a estabilidade das Contas Públicas. O segundo, na ampliação das transferências intergovernamentais a partir de 1998, principalmente condicionadas à saúde (Sistema Único de Saúde - SUS) e educação (o antigo Fundo de Manutenção e Desenvolvimento do Ensino Fundamental e de Valorização do Magistério - FUNDEF - que se transformou em dezembro de 2006 no atual Fundo de Manutenção e Desenvolvimento da Educação Básica e de Valorização dos Profissionais da Educação - FUNDEB).

No âmbito mais geral, a LRF estipulou para Estados e municípios um limite superior para gastos com pessoal em $60 \%$ da receita corrente líquida. Para evitar o endividamento excessivo, também estipulou uma relação de 1,2 entre a dívida consolidada líquida e a receita corrente. Além disso, definiu metas fiscais anuais e a exigência de apresentação de relatórios trimestrais de acompanhamento. Estabeleceu, ainda, mecanismos de controle das finanças públicas em anos eleitorais e proibiu socorro financeiro entre a União e os governos subnacionais, além de estabelecer punições caso as normas estabelecidas não sejam cumpridas. ${ }^{1}$

Estudos empíricos como Fiovarante et al. (2006), Menezes (2005) e Giuberti (2005) demonstram que a LRF foi eficaz na redução dos déficits públicos municipais. No entanto, estes trabalhos identificaram um "erro de calibragem" na imposição de $60 \%$ da despesa com pessoal como proporção da receita, dado que apenas uma minoria

1 Os Tribunais de Contas Estaduais, em caso de não cumprimento da Lei por parte do Estado e dos municípios, envia ao Ministério Público a informação para providências. Não se conseguiu informação de prefeitos já punidos pelo descumprimento da LRF em si, embora haja vários casos, não só no Estado de Minas Gerais, de processos por não aprovação das contas dos municípios. 
dos municípios brasileiros ultrapassava esse teto. Neste sentido, a imposição de um limite superior estimulou o aumento desse tipo de despesa para a maioria dos municípios que apresentavam gastos muito inferiores ao teto. Os motivos que causaram este comportamento dos gastos, abordados pelos autores supracitados, são variados, mas podem ser resumidos pelo comportamento oportunista do político.

Deve-se destacar, contudo, que a LRF não objetiva determinar níveis de gastos específicos, mas sim, regulamentar as Finanças Públicas em todos os níveis. Todavia, à medida que se identifiquem dispositivos que indiretamente engessem os instrumentos fiscais, a LRF pode "atar as mãos" das esferas políticas locais quando algum nível de discricionariedade é desejável para combater crises econômicas. Assim, não obstante os benefícios da LRF em termos de transparência da condução da política fiscal e redução de déficits, a imposição de regras pode induzir à limitação da participação efetiva do governo na política fiscal anticíclica.

Menezes (op. cit.) realiza um abrangente estudo sobre o comportamento das despesas municipais antes e depois da LRF. Para tanto, o autor analisou as despesas por funções - sociais, infraestrutura e overhead - e por categorias - orçamentária, corrente, com pessoal, capital, juros e encargos da dívida, investimento e amortização. Suas conclusões apontam que os ajustes promovidos pela Lei ocorreram mediante redução nos componentes menos rígidos dos gastos, especificamente a despesa por função infraestrutura e a despesa por categoria econômica de investimento. Basicamente, isto ocorre porque na divisão das despesas por funções a despesa com educação e saúde apresenta forte rigidez devido à vinculação das receitas provenientes do FUNDEF e do SUS, respectivamente. Ademais, a rubrica gasto com pessoal, que reúne despesas com salários, assistência social, previdência social e treinamento, apresenta forte rigidez, sendo difícil implementar cortes nessa área.

O presente trabalho procura identificar, empiricamente, os efeitos do aumento das transferências e da LRF sobre as despesas de pessoal e investimento nos municípios mineiros. A razão para este estudo deve-se aos proeminentes efeitos que as despesas de pessoal e de investimento podem ocasionar nas conjunturas municipais. Por meio dessas despesas, a administração pública pode interferir e produzir efeitos representativos mediante a forma com que estes gastos incidem sobre os ciclos ou mesmo no crescimento econômico. Decisões de gastos com pessoal e com investimento podem ainda ser utilizadas como indicador de aprovação populacional o que, por sua vez, pode acarretar a permanência ou a troca do partido que detém o poder local nas eleições. O objetivo é mostrar que, associado ao caráter de dependência de recursos que a Constituição acarretou aos municípios, a LRF ainda pode ter promovido alterações sobre a forma de alocação das despesas. 
Este trabalho inova no tocante à metodologia econométrica utilizada para obter relações entre gastos e receitas. Os trabalhos de Fiovarante et al. (op. cit.), Menezes (op. cit.) e Giuberti (op. cit.) ao utilizarem resultados econométricos para caracterizar os determinantes das despesas, não atentam para a possibilidade de simultaneidade entre variáveis. O presente artigo contribui ao apresentar uma metodologia econométrica para estimar relações causais entre receitas e despesas eliminando problemas de endogeneidade nas variáveis. Isto, por sua vez, pôde corrigir eventuais inconsistências nos parâmetros estimados.

Na próxima seção apresenta-se uma análise sobre o comportamento das variáveis de despesas e receitas nos municípios mineiros ao longo de 1995 até 2005. O tópico posterior apresenta a metodologia econométrica a ser utilizada neste trabalho e o seguinte mostra os resultados, discutindo, basicamente, as elasticidades das receitas correntes em relação às despesas estudadas antes de depois da promulgação da LRF. Finalmente, um último tópico é destinado às conclusões.

\section{DESPESAS COM PESSOAL E COM INVESTIMENTO NOS MUNICÍPIOS MINEIROS E SUAS RELAÇOEES COM A LEI DE RESPONSABILIDADE FIS- CAL E TRANSFERENCIAS INTERGOVERNAMENTAIS}

A Lei de Responsabilidade Fiscal foi implantada com o objetivo de romper de forma definitiva o círculo vicioso de pacotes emergenciais para socorrer governos em dificuldades, bem como evitar a utilização de forma sistemática do ciclo político. Neste caso, o comportamento oportunista de final de mandato, conhecido como "Ciclo Político Eleitoral", tende a diminuir.

Desde a sua promulgação, a mudança no comportamento dos administradores públicos é inegável. As contas públicas apresentam, atualmente, uma situação melhor do que nos períodos anteriores à instituição da LRF. A Tabela 1 apresenta o desempenho orçamentário dos municípios antes e depois da promulgação da Lei (2000), a preços de 2005. A partir de 2000, os municípios, em termos agregados, deixam de acumular déficits e passam a apresentar consecutivos superávits. Apesar desses resultados positivos, a LRF deve ser analisada criticamente. Uma série de fatores demonstra que, embora tenha trazido novos conceitos, novas diretrizes e resultados positivos, ela pode provocar algumas distorções no equilíbrio federativo, prejudicando a execução de políticas que tenham o intuito de diminuir os desequilíbrios regionais. 


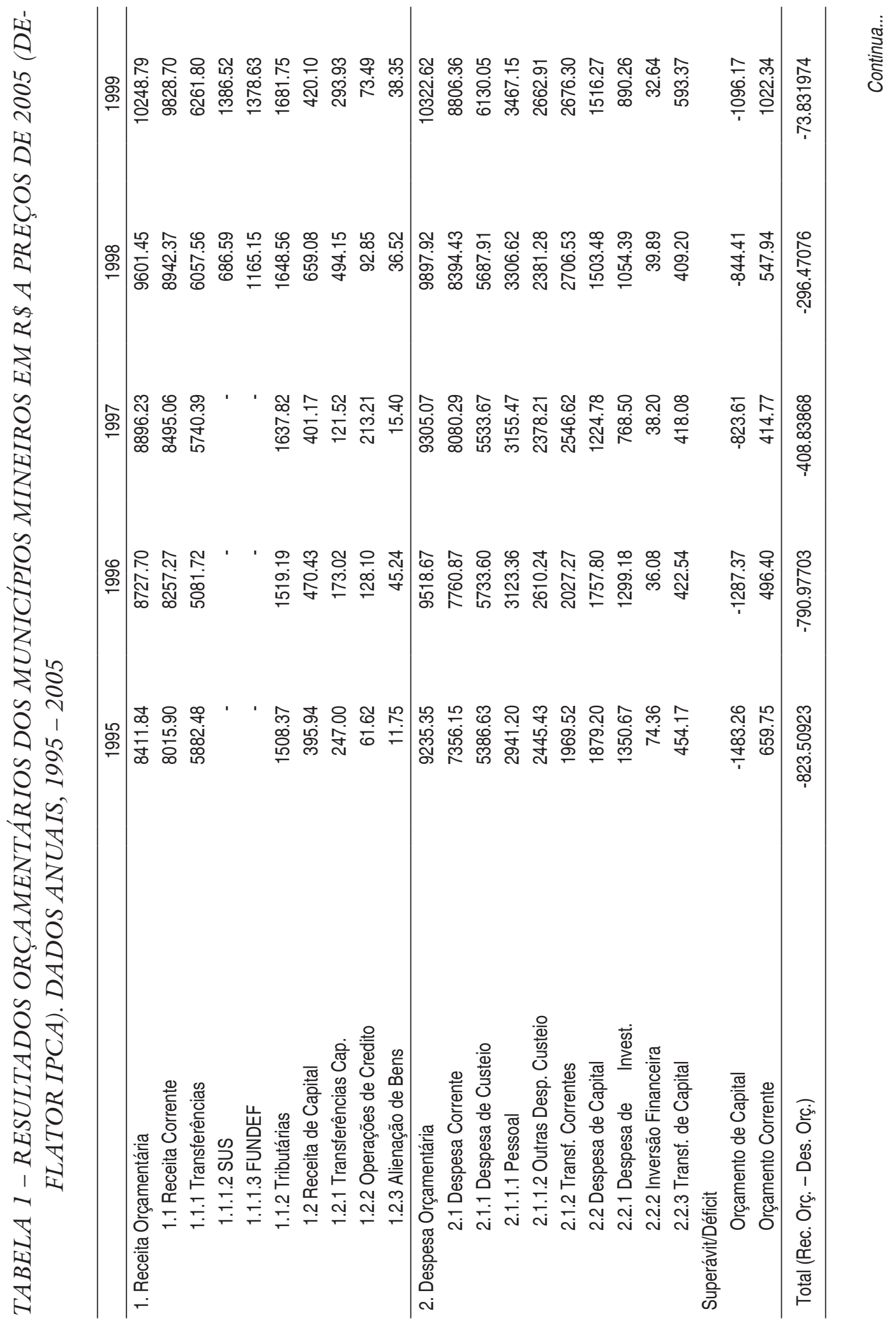




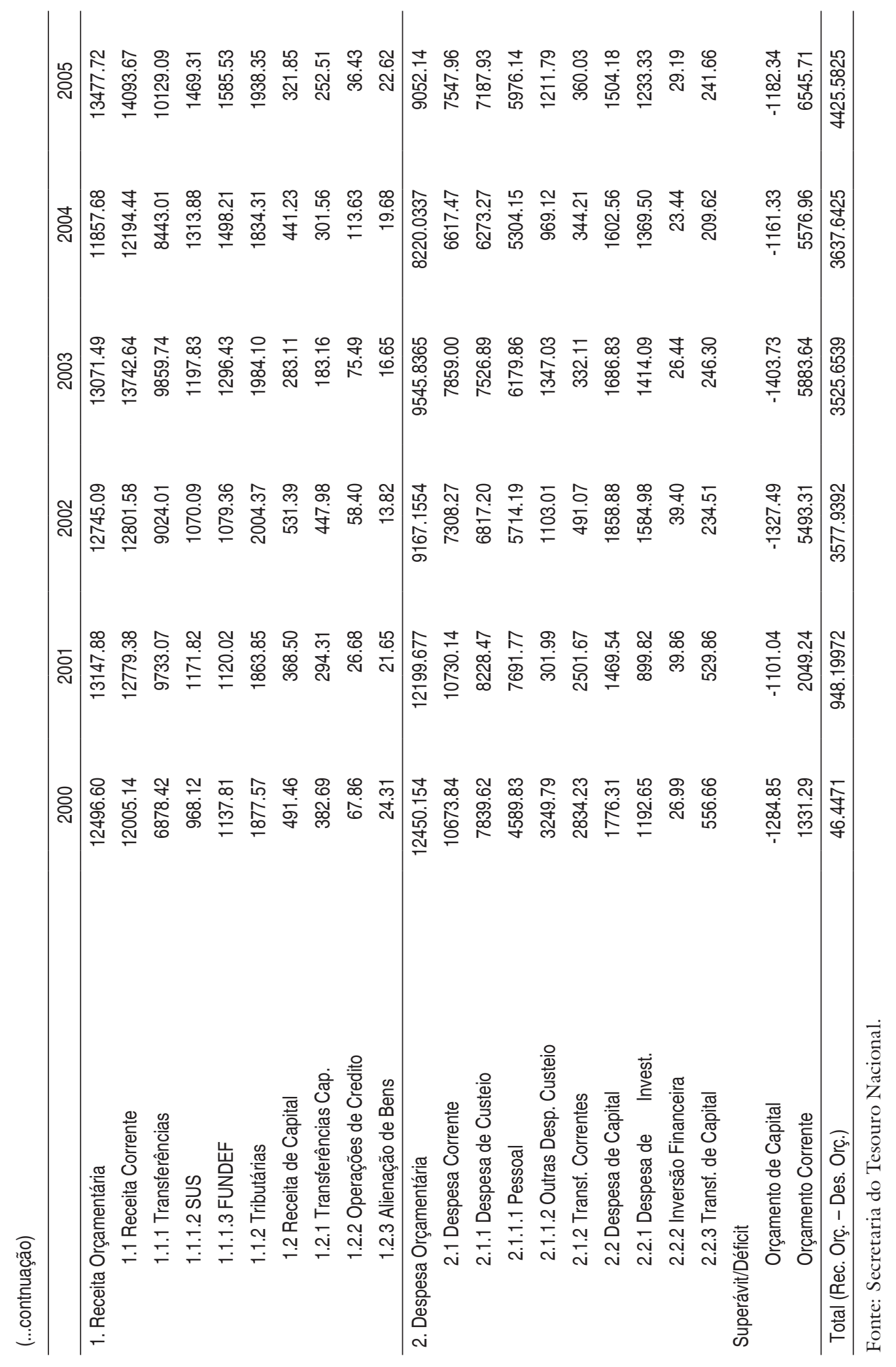


De fato, do ponto de vista da "accountability", a LRF é certamente um resultado positivo, uma vez que a necessidade de prestar contas à sociedade obriga os administradores públicos a garantirem minimamente o cumprimento do orçamento votado. No entanto, a rigidez na aplicação dos gastos, principalmente gastos de pessoal, trata igualmente os desiguais. Municípios muito pequenos e com baixa geração de renda em geral têm, no poder municipal, o principal empregador local. Eventualmente a folha de pessoal, menos do que servir apenas a interesses clientelistas, pode ser central para garantir renda mínima a parcela da população local. A limitação dos gastos em $60 \%$ pode inviabilizar a determinadas prefeituras funcionarem como "empregadores em última instância” e acentuar os desequilíbrios regionais. Com efeito, a capacidade de investimentos de alguns municípios com menos de 5.000 habitantes é mínima. Os grandes municípios, por seu turno, raramente ultrapassavam o limite de gastos impostos pela lei antes de sua promulgação.

Com rígidas regras imputáveis a todos os entes federados, a Lei de Responsabilidade Fiscal apresenta uma série de objetivos complementares, como o amplo acesso às informações referentes à administração pública, transparência nos procedimentos de arrecadação e de aplicação dos recursos públicos através da divulgação frequente dos resultados alcançados e de metas para os exercícios futuros. Todavia, o enfoque maior dessa legislação recai sobre o controle do endividamento público.

A descrição sobre as regras e punições referentes ao comportamento dos principais gastos públicos é útil para se ter uma visão concreta do teor dessa Lei. Conforme explicita Tavares et al. (1999), além do endividamento público nas esferas municipais, outras variáveis devem ser controladas pelas administrações públicas, basicamente o aumento dos gastos de duração continuada e gastos públicos com pagamento de funcionários. $\mathrm{O}$ rigor quanto às regras e punições é uma importante característica da LRF e, certamente, apresenta fatores que não podem ser esquecidos na avaliação dos impactos da LRF nos seus campos de atuação.

A categoria de gasto com despesa continuada, que se caracteriza por apresentar efeitos que ultrapassam três exercícios financeiros, é regida pelo processo de compensação. Assim, se houver um aumento dos gastos, por exemplo, em contratação de novos funcionários ou diminuição das receitas, seja através de renúncia fiscal, subsídios ou qualquer outro benefício que diminua a arrecadação, cortes em outras áreas relacionadas a esses gastos deverão ser feitos ou então novas fontes de recursos devem ser criadas. Todavia, se o aumento dos gastos for proveniente de aumento das despesas com os serviços da dívida ou se for um aumento das despesas de capital financiadas por operações de crédito, doações ou transferências voluntárias, esses não precisam ser compensados. 
Em relação aos gastos com pessoal, um dos pontos mais polêmicos da Lei devido à sua rigidez, o princípio da compensação também se aplica. Um aumento de gastos com pessoal em decorrência de concessão de aumento de salário, alguma espécie de vantagem que acarrete aumentos dos gastos, alteração e ou definição de planos de carreira e contratação de novos funcionários devem ser compensados ou por cortes em outros gastos ou por aumento de receitas. Novamente, se o aumento dos gastos com pessoal for proveniente de reajuste com o intuito de manutenção do valor real dos salários, o princípio da compensação não precisa ser respeitado.

Se as despesas com os funcionários ultrapassarem os limites estabelecidos, qualquer nova contratação, aumento, reajuste, criação de novos cargos, alteração nos planos de carreira - vale dizer, qualquer movimento do governo em favor do aumento dos gastos com pessoal fica expressamente proibido até que a situação volte aos níveis estabelecidos.

Se, por outro lado, as despesas com pessoal ultrapassarem os limites por três meses consecutivos, o ente federado tem um prazo de dois anos para se enquadrar nos limites impostos pela lei. Esse enquadramento deve ser feito através de demissão de servidores não estáveis, extinção de cargos de confiança ou até mesmo demissão de funcionários concursados. Se ao final desses dois anos as despesas com o funcionalismo não tiverem sido regularizadas, todos os repasses de recursos para o município ficam suspensos. Não é permitido que níveis superiores de governo concedam empréstimos a níveis inferiores para o pagamento de funcionários.

A Figura 1 apresenta um diagrama de dispersão da relação Gasto com Pessoal/ Despesa Corrente dos municípios antes e após a promulgação da Lei. É possível identificar dois aspectos importantes. O primeiro é que poucos municípios ultrapassavam os limites de gastos com pessoal em 1995 (antes da vigência da Lei), embora a dispersão fosse muito grande. O segundo aspecto é que a LRF acabou gerando uma menor dispersão desses gastos, vale dizer, paulatinamente todos os municípios foram se enquadrando nos limites impostos pela LRF. Precisamente, apenas um município ultrapassava o limite dos 60\% de Gastos com Pessoal/Receita Corrente em 2005.

Curiosamente, é possível observar que, ao estimular uma concentração dos Gastos com Pessoal em torno de $40 \%$ a $60 \%$ da Receita Total, muitos municípios que estavam abaixo deste patamar ampliaram esses gastos. Isto se deve ao fato de que, antes da implantação da LRF, não havia normas claras a orientar o processo de alocação dos gastos públicos com pessoal. Na ausência de uma indicação explícita acerca do nível adequado desses gastos, tal rubrica orçamentária estava sujeita a avaliações subjetivas por parte de cada município no que tange a seu nível ideal/aceitável. Neste critério subjetivo, poucos municípios superdimensionavam suas despesas com 
pessoal (tomando como base o nível máximo de 60\%), enquanto a maior parte as subdimensionava.

FIGURA 1 - RELAÇÃO ENTRE DESPESA COM PESSOAL/RECEITA CORRENTE (EIXO VERTICAL) E NÚMERO DE IDENTIFICAÇÃO DO MUNICÍPIO (EIXO HORIZONTAL) DOS MUNICÍPIOS MINEIROS PARA O ANO 1995 A 2005
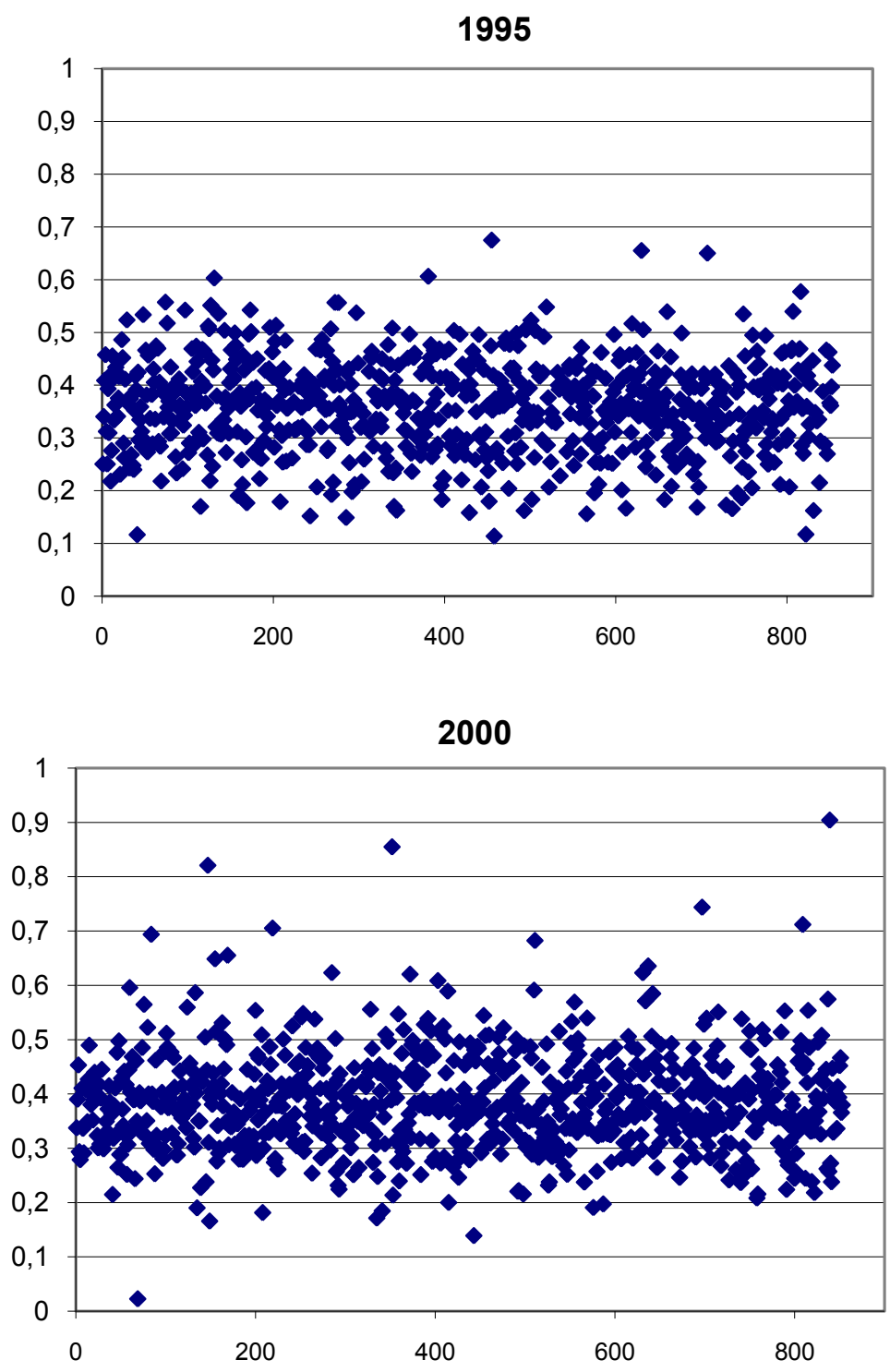


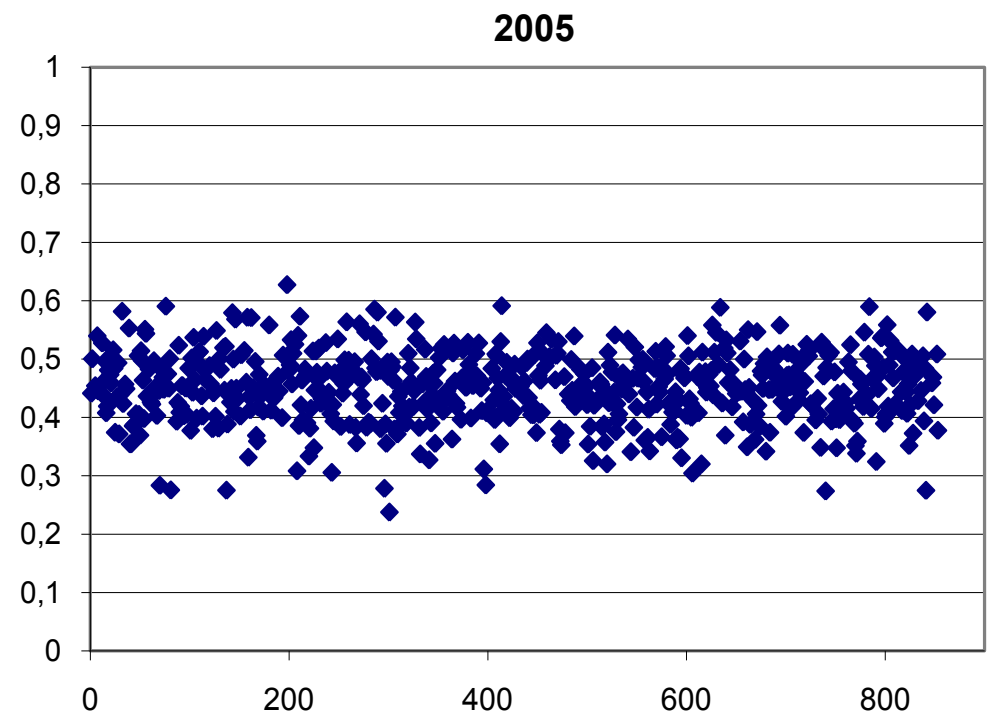

Fonte: Elaboração própria com dados da Secretaria do Tesouro Nacional.

Deve-se destacar que, implícita neste argumento, está a noção de que gastos com pessoal podem ser convenientes politicamente nos acordos eleitorais. Dado isto, o administrador público enfrenta um problema de avaliação de risco. Antes da LRF, gastos excessivos com pessoal poderiam dificultar negociações com esferas superiores (Estados e governo federal, bem como credores). Assim, cada município utilizava sua própria estimativa subjetiva acerca de qual seria o nível aceitável de despesas com pessoal ao compor seu orçamento. As diferenças verificadas antes da LRF devemse a estes diferentes julgamentos acerca do nível aceitável de despesas sob a referida rubrica.

Neste contexto, tendo a LRF sancionado explicitamente qual o nível aceitável de despesas com pessoal, verifica-se uma tendência de convergência entre as parcelas relativas que cada unidade municipal aloca para tais gastos, induzindo aqueles que gastavam demais a gastarem menos, porém, igualmente, induzindo os cautelosos, que gastavam menos, a gastarem mais. Assim, a LRF, ao sancionar explicitamente um nível de tolerância, induz a uma uniformização dos gastos com pessoal através dos diversos municípios. Naturalmente que, diante de uma eventual rigidez real das Receitas Totais, o aumento dos gastos de pessoal pode vir acompanhado de queda de gastos com investimentos.

No caso das despesas de capital, a situação é distinta das despesas correntes. Resumidamente, elevações nas Despesas de Capital só podem lograr êxito caso haja elevações nas Receitas de Capital. 
Com relação às operações de crédito, se essas forem feitas em discordância com as regras preestabelecidas, seus efeitos deverão ser imediatamente anulados por meio de cancelamento ou pagamento total da dívida adquirida através da constituição de um fundo de reservas exclusivo para o pagamento dessa dívida. O ente federado, enquanto não resolver esse problema, fica proibido de realizar novas operaçóes de crédito.

Caso algum ente da federação ultrapasse o montante da dívida estabelecida, ele deve realizar cortes até que a dívida volte aos patamares preestabelecidos. Enquanto isso, fica proibido de realizar qualquer operação de crédito e suas despesas ficam restringidas. Se esse ente federado não respeitar os prazos estabelecidos para a reorganização de suas contas, os repasses de recursos federais destinados a ele serão suspensos até que sua situação financeira se estabilize novamente. Nesses repasses de recursos não estão incluídos os repasses referentes às vinculações tributárias.

Com relação ao endividamento público, as operações de crédito não podem ser maiores, em valor, do que as despesas de capital em um mesmo exercício financeiro. Isso é uma forma de coibir uma prática amplamente difundida nos anos 1980, quando os governos se financiavam através de seus bancos estaduais. Os governos também ficam proibidos de atrasar pagamentos a fornecedores e prestadores de serviço dando-lhes em troca títulos de crédito. Assim, embora a LRF não tenha determinações específicas acerca da despesa de investimento, as punições que constam da LRF enrijecem sobremaneira as fontes de financiamento desta despesa. Por este motivo é importante, inicialmente, compreender como os municípios podem utilizar seus recursos disponíveis para realizar gastos de investimento.

A receita de capital é proveniente da realização de recursos financeiros oriundos da constituição de dívidas, da conversão em espécie, de bens e direitos, dos recursos recebidos de outras pessoas de direito público ou privado destinados a atender despesas classificáveis em despesas de capital e, ainda, do superávit do orçamento corrente. ${ }^{2}$ De acordo com a Tabela 1 , em todo período, as despesas com investimentos são superiores às receitas de capital. Por isso, parte das despesas de investimento são financiadas por meio do superávit corrente e por operações de crédito que acarretavam o déficit no orçamento. Após 2001, as operações de crédito (como Adiantamentos de Receita Orçamentária - ARO) são proibidas, de modo que o financiamento das despesas de capital necessariamente passou a ser feito com as Receitas Correntes.

A Figura 2 apresenta a relação despesa de investimento/receita orçamentária de cada município mineiro e confirma uma diminuição da dispersão após 2000. Há, portanto, um padrão de convergência das despesas de investimento, tal como pode ser

2 Ministério da Fazenda, Secretaria do Tesouro Nacional (Min. Fazenda/STN). 
vislumbrado na despesa com pessoal. Enquanto os dados indicavam uma intensa dispersão desta rubrica no ano de 1995, a partir de 2000 verifica-se uma gradativa concentração para a faixa entre 0 a $20 \%$.

FIGURA 2 - RELAÇÃO ENTRE COEFICIENTE DESPESA COM INVESTIMENTO/RECEITA CORRENTE (EIXO VERTICAL) E NÚMERO DE IDENTIFICAÇÃO DO MUNICÍPIO (EIXO HORIZONTAL) DOS MUNICÍPIOS MINEIROS PARA OS ANOS DE 1995 A 2005

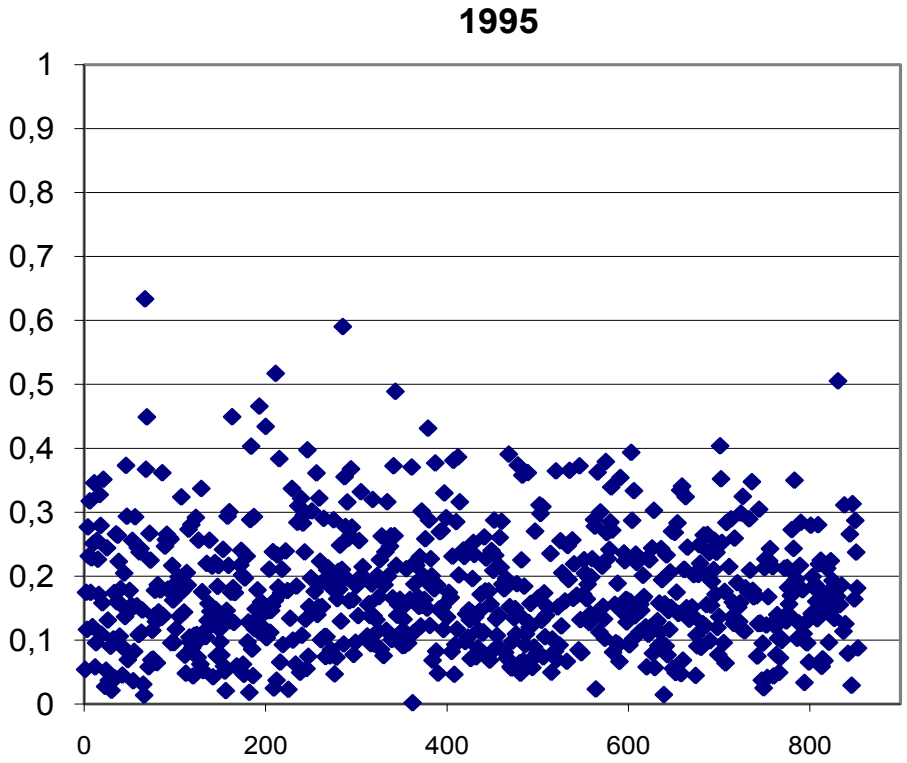




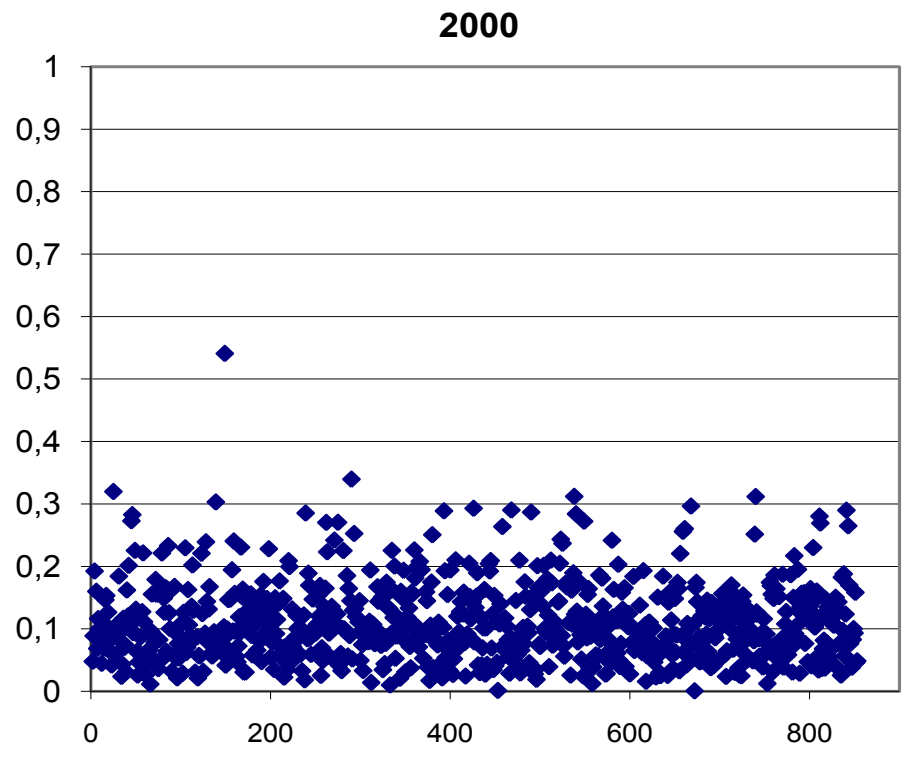

2005

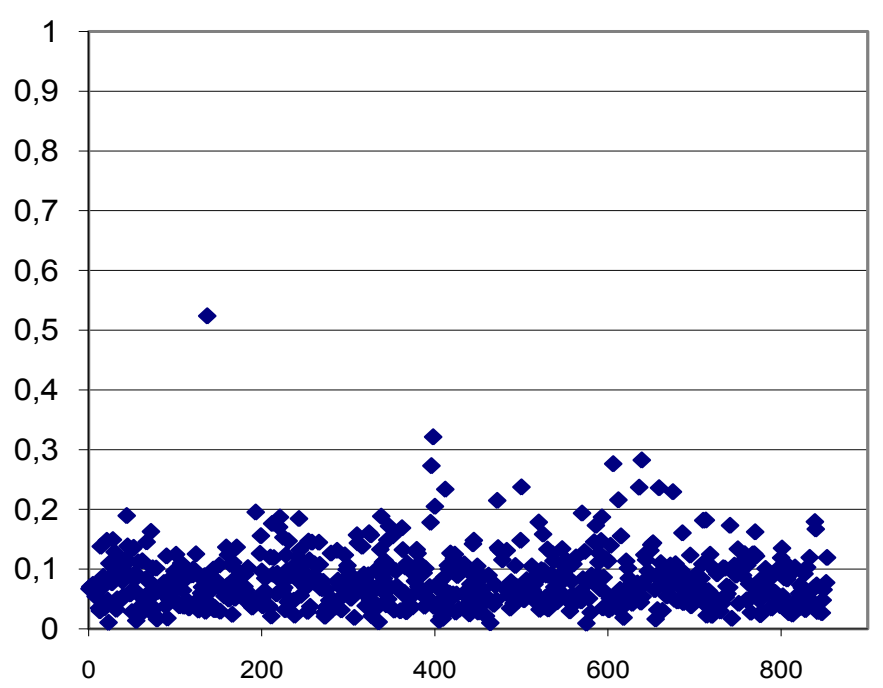

Fonte: Elaboração própria com dados da Secretaria do Tesouro Nacional.

A interpretação destes resultados, que parecem estar associados diretamente à implementação da LRF, pode ser mais bem qualificada de acordo com os dados da Tabela 1. Uma análise dos dados de receitas ali apresentadas demonstra que o crescimento receita orçamentária, a partir de 1998, foi da ordem de $47 \%$ em termos reais. Ao todo, a receita tributária apresentou um crescimento total de $20 \%$ enquanto as re- 
ceitas de transferências se expandiram em $78 \%$. Por sua vez, as despesas com pessoal cresceram $98,5 \%$ e os gastos de investimento $21,5 \%$.

Tal fato deve-se ao aumento das transferências condicionadas ao SUS e FUNDEF, o que levou ao aumento de responsabilidades dos municípios dentro da federação brasileira (AFONSO, 2004). ${ }^{3}$ Vale ressaltar que o SUS não impõe nenhuma regra para as alocações de recursos. Por seu turno, o FUNDEF impõe que pelo menos $60 \%$ dos gastos sejam realizados com professores, ou capacitação dos mesmos, e $40 \%$ com manutenção da estrutura. Como pode ser observado, ambas as transferências têm participação relativamente alta nas transferências correntes. Em conjunto, o percentual de participação do SUS e FUNDEF é, em termos médios, de $25 \%$ a $30 \%$.

Como apenas o FUNDEF vincula diretamente as transferências com gastos de pessoal, isto significa que ao menos $10 \%$ das transferências correntes devem, obrigatoriamente, ser gastas com pessoal. Os outros $90 \%$ ficam a cargo das decisões do administrador público municipal. Estes dados permitem concluir que as transferências vinculadas não exercem uma pressão alta o suficiente para se explicar os padrões de convergência detectados nas Figuras 1 e 2, bem como o crescimento acumulado de quase $100 \%$ dos gastos com pessoal ao longo de 6 anos.

À luz destes dados, pode ser verificado que os gastos com pessoal dos municípios aumentaram não necessariamente apenas em virtude da queda das despesas com investimento. Naturalmente, como os gastos com pessoal e as transferências correntes se elevaram, a relação gastos de investimento/ receitas totais pode ter se reduzido caso a despesa de investimento não tenha acompanhado o mesmo ritmo de crescimento da receita total.

Assim, o modelo econométrico deve avaliar duas possíveis hipóteses. A primeira é analisar se os municípios mineiros têm aumentado suas despesas de pessoal em razão da queda das despesas de investimento. Neste caso, deve ser observada uma relação direta entre as fontes de receitas e a despesa de pessoal, mas inversa com a despesa de investimento. A segunda hipótese é de que a elevação das despesas com pessoal não se deve ao decréscimo das despesas com investimento, mas sim, em virtude do aumento das transferências correntes. O próximo passo, então, é apresentar uma metodologia econométrica capaz de verificar as hipóteses aqui levantadas acerca do papel da LRF sobre execução de despesas dos municípios, relacionando as fontes de receitas com as despesas supracitadas.

3 As transferências promovidas pelo SUS representam cada vez mais uma parte importante da descentralização de recursos, porquanto, estas têm atingido níveis de $15 \%$ do total dos impostos federais repartidos, sendo 79\% desses recursos destinados aos municípios (AFONSO, 2004). 


\section{MATERIAL E MÉTODOS}

\subsection{Modelo Econométrico e Método de Estimação}

Vários modelos realizam pressuposições a respeito das relações de causalidade em finanças públicas. Friedman (1978) defendia que a relação causal era do tipo taxar e gastar. Segundo ele, qualquer ajuste nas receitas pode ser suportado pelas despesas. Um modelo teórico que produz esta relação é Niskanen (1971) pelo qual a maximização da função utilidade do burocrata deve ter uma restrição orçamentária que proíbe déficits.

Já Barro (1979) e Peacock e Wiseman (1979) propuseram que os gastos precedem as taxas, ou seja, a relação se dá no sentido de que os gastos determinam as receitas. Segundo Peacock e Wiseman (ibidem), em momentos de crises econômicas, governantes tendem a aumentar seus gastos. No entanto, após o término da recessão, a restrição orçamentária não recupera sua posição original. Por sua vez, o modelo de tax-smoothing, proposto por Barro (op. cit.), indica que o acúmulo de dívidas resulta da maximização da função de bem-estar dos indivíduos governados por um "planejador benevolente" que obtém receita da tributação da renda dos trabalhadores. Neste sentido, em períodos recessivos o governo aumenta os gastos para evitar distorções associadas a flutuações da política fiscal. Por seu turno, nos períodos de expansão do produto o governo aumenta o superávit.

Uma terceira possibilidade é a de que receitas mudam correntemente com os gastos. Esta é a hipótese mais aceita pelos livros textos em geral, pelos quais os custos marginais e as receitas marginais se equilibram uns aos outros. Se for este o caso, então as arrecadações e os gastos são selecionados mutuamente. Exemplos desta teoria implicam uma relação causal mútua intertemporal; tal versão pode ser encontrada no teorema do voto mediano de Black (1958).

Por último, existe a possibilidade de que as receitas e os gastos mudem independentemente uns dos outros. Isto ocorreria no caso em que os níveis de gastos estariam determinados por regras fixas. Esta circunstância é consistente com o modelo de consumo de Hall (1978), pelo qual o consumo corrente é determinado apenas pelo consumo passado.

Há, finalmente, modelos keynesianos que observam o papel anticíclico da política fiscal. Vale dizer, em momentos de insuficiência de demanda agregada o governo utiliza a política fiscal como elemento dinamizador da renda e o contrário em períodos de baixa capacidade ociosa ou superemprego. Neste caso, para evitar pressões 
inflacionárias o governo contrai a política fiscal. O papel do formulador de política econômica, em uma combinação virtuosa de política fiscal e monetária, é central como estabilizador de renda e emprego, bem como da inflação. Observe que a LRF em certo sentido subverte o papel estabilizador do planejador ao impor restrições excessivas à manipulação da política fiscal. Por outro lado, ao disciplinar o planejador, evita ações desestabilizadoras e ciclos políticos. ${ }^{4}$

Dada a indeterminação teórica relativa ao sentido da causalidade entre receitas e gastos - bem como do fato de que a LRF implicitamente impõe uma relação direta entre gastos e receitas - Dahlberg e Johansson (2000) propuseram que a análise empírica deste relacionamento fosse realizada por meio de um modelo de painel dinâmico ou panel-var formalizado originalmente por Holtz-Eakin, Newey e Rosen (1988). Neste modelo econométrico todas as covariadas são tratadas como endógenas.

O modelo é formado pela seguinte equação de interesse:

$$
\operatorname{Des}_{i, t}=\alpha_{t 0}+\sum_{j=1}^{m} \beta_{j} \operatorname{Des}_{i, t-j}+\sum_{j=1}^{m} \gamma_{j} R \operatorname{Tri}_{i, t-j}+\sum_{j=1}^{m} \delta_{j} \operatorname{RTrans}_{i, t-j}+f_{i}+\varepsilon_{i t}
$$

em que $i=1, \ldots, N=853, m$, o tamanho da defasagem a ser adotada e $t=m+1$, $\ldots$, , 4. Des $s_{i, t}, R \operatorname{Tr}_{i, t}$, e $R \operatorname{Trans}_{i, t}$ são, respectivamente, as despesas, as receitas tributárias e as receitas de transferências, todas as variáveis são per capita e em logaritmo. $\alpha_{t 0}$ é uma variável dummy de tempo para controlar choques macroeconômicos e de ciclos políticos que afetam todos os municípios da mesma forma. $f_{i}$ são os efeitos fixos municipais não observados e captam características que não variam no tempo, como localização geográfica, os quais não são explicitados como sendo de efeito fixo ou aleatório.

Inicialmente, o procedimento padrão utilizado para estimar painel dinâmico baseiase em Arellano e Bond (1991). O argumento é tomar as primeiras diferenças da equação original em nível para eliminar o efeito fixo das regiões $i$ e, assim, remover a fonte de inconsistência do modelo. Os coeficientes são estimados pelo Método de Momentos Generalizados (Generalized Method of Moment, GMM), e o problema da endogeneidade é tratado com técnicas de variáveis instrumentais que incluem recursivamente todos os valores passados das variáveis endógenas do modelo. Sob as pressuposições de não-autocorrelação serial no termo de erro, o estimador fornecido por esta metodologia é consistente e eficiente. Adicionalmente, ao usar os níveis da

4 Para uma boa análise do papel da política fiscal em modelos keynesianos, ver Taylor (2004), especialmente capítulos 6 e 7, bem como Wray (1998, cap. 4). 
variável explicativa defasada, ao menos dois períodos como instrumentos, este estimador também reduz o problema de endogeneidade das variáveis explicativas.

Os sistemas de equações dinâmicas podem ser estimados como segue:

$$
\Delta D e s_{i, t}=\Delta \alpha_{t 0}+\sum_{j=1}^{m} \beta_{j} \Delta \operatorname{Des}_{i, t-j}+\sum_{j=1}^{m} \gamma_{j} \Delta R \operatorname{Tri}_{i, t-j}+\sum_{j=1}^{m} \delta_{j} \Delta R \operatorname{Trans}_{i, t-j}+u_{i t}
$$

onde $\Delta$ representa a primeira diferença e $u_{i, t}=\varepsilon_{i, t}-\varepsilon_{i, t-1}$. Isto remove o efeito fixo e deixa apenas o efeito do tempo. A dimensão da defasagem máxima, dada a quantidade de 11 anos, é fixada em $m=4 .^{5}$

Contudo, devido à fraca correlação entre as variáveis defasadas em níveis e as subsequentes primeiras diferenças, em muitos casos estas séries demonstram ser instrumentos pobres para as variáveis em primeira diferença, especialmente para as séries altamente persistentes (ARELLANO; BOVER, 1995).

Arellano e Bover (ibidem) propõem um estimador aumentado que inclui, além das variáveis em primeira diferença, as equações originais em níveis dentro do sistema GMM. Neste contexto, a estimativa, não somente melhora a precisão, como também reduz o viés de amostra finita.

A especificação do modelo é examinada através de um teste de validade das restrições de sobreidentificação (validade da exclusão dos instrumentos) fornecida pelo Teste de Sargan. A estatística do teste de sobreidentificação, que capta os desvios das restrições de momento "em excesso", tem distribuição assintótica. Esta restrição é testada utilizando critérios da função GMM, que tem formulação baseada sobre o recálculo dos resíduos após a estimação da equação (2).

$$
q=\left(\sum_{i=1}^{n} \hat{u}_{i}^{\prime} Z_{i}\right) W\left(\sum_{i=1}^{n} Z_{i}^{\prime} \hat{u}_{i}\right)
$$

sob hipótese nula $q$ tem uma distribuição assintoticamente $\chi^{2}$ com graus de liberdade $(D f)$ igual ao número de instrumentos subtraído o número de parâmetros estimados.

A utilização dos métodos Arellano e Bond (op. cit.) ou Arellano e Bover (op. cit.) dependerá do teste de sobreidentificação realizado em cada equação estimada. Embora o estimador de Arellano e Bover apresente a vantagem quanto ao ganho de con-

5 No decorrer do texto será explicado o motivo para o tamanho máximo da defasagem ser de quatro períodos. 
sistência, a sua principal limitação diz respeito ao aumento da probabilidade de ser rejeitado no teste de sobreidentificação. Isto ocorre porque o método Arellano e Bover utiliza um número muito superior de instrumentos do que o método de Arellano e Bond (op. cit) o que, por sua vez, aumenta a possibilidade de correlação entre as variáveis utilizadas. Neste caso, o critério adotado foi, inicialmente, estimar a equação por Arellano e Bover (op. cit.), priorizando a consistência que o método oferece. Caso o teste de Sargan rejeite a validade dos instrumentos, então utiliza-se o método de Arellano e Bond.

A especificação correta das relações dinâmicas entre receitas e gastos municipais consiste em detectar o número de defasagens apropriadas das variáveis covariadas. Seguindo as orientações de Dahlberg e Johansson (op. cit.), a identificação estatística do tamanho apropriado das defasagens inicia-se pela escolha de número $\tau$ de defasagens para as variáveis independentes. A estimativa da equação com o número máximo de defasagens é denominada modelo irrestrito. As equações de menores defasagens são ditas modelo restrito.

O teste da diferença de Sargan $(d s)$ é feito obtendo-se o valor $q$, fornecido pela equação (3). A estatística $d s$ é formada estimando o modelo restrito $(R)$ e o modelo irrestrito $(U)$ e então calcula-se $d s=q_{R}-q_{U}$. Sob a hipótese nula de que o modelo correto é o restrito, $d s$ tem uma distribuição assintoticamente $\chi^{2} \operatorname{com} D_{d s}=D f_{q_{R}}-D f_{q_{U}}$ graus de liberdade.

Assim, Dahlberg e Johansson (ibidem) apresentam as seguintes diretrizes para se testar a melhor especificação do modelo:

i. Estimar a equação (3) para uma dada defasagem máxima escolhida a priori e obter $q_{U}$

ii. Realizar o teste de Sargan para restrição de sobreidentificação e checar se a hipótese de correta especificação do modelo não pode ser rejeitada;

iii. Reduzir a equação estimada em (i) em uma defasagem, isto é, tomam-se $\tau-1$ defasagens. Obtém-se $q_{R}$, e verifica-se se a hipótese de que a redução da defasagem é válida não pode ser rejeitada. Caso seja, passa-se a (iv). Do contrário, tem-se o modelo irrestrito como a especificação correta;

iv. Repetir o passo (iii) até que a especificação correta seja encontrada, ou até que a dinâmica do modelo seja eliminada. 
Para identificar os efeitos que a LRF pode ter acarretado nas despesas dos municípios as regressões foram realizadas incluindo dummies nas variáveis no período posterior à promulgação da LRF, isto é, a partir do ano 2001. Seguindo a modelagem proposta em Wachter e Tzavalis (2004) para estimar regressões em painel dinâmico com quebras estruturais, as equações objetivadas na análise tomam o seguinte formato:

$$
\begin{aligned}
& \operatorname{Des}_{i, t}=\alpha_{t 0}+\sum_{j=1}^{m} \beta_{j} \operatorname{Des}_{i, t-j}+\sum_{j=1}^{m} \gamma_{j} R \operatorname{Tri}_{i, t-j}+\sum_{j=1}^{m} \delta_{j} \operatorname{RTrans}_{i, t-j}+f_{i}+\varepsilon_{i t} \quad t<\tau \\
& \operatorname{Des}_{i, t}=\alpha_{t 0}+\sum_{j=1}^{m}\left(\beta_{j}+\omega_{j, \tau}\right) \operatorname{Des_{i,t-j}}+\sum_{j=1}^{m}\left(\gamma_{j}+\mu_{j, \tau}\right) R \operatorname{Tr} i_{i, t-j}+\sum_{j=1}^{m}\left(\delta_{j}+\xi_{j, \tau}\right) \operatorname{Rrans}_{i, t-j}+\left(f_{i}+\vartheta_{i, \tau}\right)+\varepsilon_{i t} \quad t \geq \tau
\end{aligned}
$$

em que $\tau$ é o ano de quebra estrutural, no presente estudo, o ano de 2001.

Assim, a estimativa da regressão (5) separa os parâmetros estimados de receitas no período antes e depois da LRF. Neste sentido, o modelo é capaz de identificar se a LRF acarretou efeitos nas decisões de despesas nos municípios. Além disso, Wachter e Tzavalis (ibidem) demonstram que, na presença de quebras estruturais lineares, as estimativas GMM tornam-se viesadas assintoticamente quando não se inclui a quebra estrutural na estimativa. Finalmente, o tamanho máximo utilizado nas estimativas parte de $m=4$. Isto foi realizado baseando-se em duas circunstâncias: a primeira deve-se à disponibilidade dos dados, que permitem verificar o efeito máximo de quatro defasagens sobre a LRF (2001 a 2005), e a segunda com o objetivo de captar igualmente os efeitos das receitas sobre despesas em períodos simultâneos antes e depois da LRF (1995 a 2000 e 2001 a 2005).

\subsection{Dados}

Os dados para as estimativas são dos 853 municípios do Estado de Minas Gerais entre os anos de 1995 a 2005 e foram obtidos na Secretaria do Tesouro Nacional (STN-FINBRA). As variáveis independentes nas equações econométricas foram avaliadas sob a perspectiva da despesa orçamentária, despesas com pessoal e com investimento em função das receitas correntes, divididas entre receita tributária e de transferências.

Em virtude das diferenças quanto à base de arrecadação de tributos, atividades econômicas, demandas e quantidade de serviços, algum critério deve ser adotado para dividir os municípios entre "grandes" e "pequenos". Para tanto, o critério adotado 
neste trabalho baseou-se na classificação do Tesouro Nacional, o qual realiza o seguinte agrupamento: 1) população inferior a 50.000 habitantes; 2) população entre 50.000 e 300.000 habitantes; 3) população entre 300.000 e 1.000 .000 de habitantes; 4) população maior do que 1.000 .000 de habitantes.

Os municípios com população menor do que 50.000 habitantes somam 790, do total de 853 municípios mineiros. Os municípios com população entre 50.000 e 300.000 habitantes respondem por 57, enquanto apenas os municípios de Belo Horizonte, Contagem, Uberlândia, Juiz de Fora, Betim e Montes Claros possuem estimativas populacionais acima de 300.000 habitantes. Por este motivo, optou-se por excluir das regressões os últimos 6 municípios e realizar a análise dos coeficientes apenas para os municípios com população inferior a 50.000 habitantes, e população entre 50.000 e 300.000 habitantes.

Como em Dahlberg e Johansson (op. cit.), os dados são per capita e transformados para logaritmos naturais. Assim, as estimativas geram diretamente os coeficientes de elasticidades. A população dos municípios também foi obtida no IPEA, tendo como fonte primária o Instituto Brasileiro de Geografia e Estatística (IBGE).

\section{RESULTADOS EMPÍRICOS}

Para melhor compreender o comportamento das variáveis utilizadas nas análises, a Tabela 2 apresenta as estatísticas de receitas e despesas per capita, em logaritmo, segmentadas em receitas tributárias e por transferências, despesas com pessoal e despesas com investimento para os municípios mineiros no período de 1995 a 2005.

As médias e os desvios padrão revelam alguns fatos acerca do comportamento destas variáveis. Como pode ser verificado, a despesa com investimento é aquela que apresenta maior variabilidade tanto dentro das cross sections municipais, como entre os anos. Por sua vez, o gasto com pessoal oferece maiores médias de gastos, e uma variabilidade menor do que a despesa de investimento.

Como visto, a rigidez no gasto com pessoal deve-se ao fato de cobrir despesas com salários, assistência social, previdência social, treinamento, além do que boa parte do funcionalismo público é formada por estatutários, portanto, uma variável de difícil corte. Por sua vez, a despesa com investimento é um componente mais discricionário, o qual não mantém vínculos entre gastos e receitas, além de variar de acordo com as necessidades do processo orçamentário e de ciclos políticos. 
Utiliza-se então o instrumental econométrico, a fim de analisar como as receitas de tributação e as oriundas das transferências constitucionais podem estar relacionadas com as despesas municipais. Neste sentido, os resultados a seguir, em parte, elucidam a forma como as prefeituras têm conduzindo a alocação dos recursos disponíveis de acordo com suas principais fontes de receitas nos municípios mineiros.

Vale ressaltar que o formato em painel das estimativas apresenta duas informações relevantes na interpretação dos parâmetros. A primeira é a informação longitudinal, controlando para todas as características quanto à localização geográfica do município e o tamanho de sua área. A elasticidade mostra como se comportam, na média, os municípios que recebem mais (ou menos) receitas tributárias e de transferências. A segunda é o caráter temporal do painel, controlando os efeitos de choques macroeconômicos e de ciclos eleitorais. A estimativa permite distinguir se houve alguma mudança significativa nas decisões de gastos municipais após a promulgação da LRF.

\section{TABELA 2 - MÉDIA E DESVIO PADR ÃO DE VARIÁVEIS PER CAPITA DE RECEITAS E DESPESAS DOS MUNICÍPIOS MINEIROS, PERÍODO $1995-2005$}

\begin{tabular}{lccc}
\hline Per Capita & & Média & Desv. Padrão \\
\hline Despesa Orçamentária Total & Inteiro & 6.045 & 1.385 \\
& Entre & & 1.316 \\
& Dentro & & 0.340 \\
\hline Receitas Tributárias & Inteiro & 2.815 & 0.981 \\
& Entre & & 0.766 \\
& Dentro & & 0.610 \\
\hline Receitas de Transferências & Inteiro & 5.937 & 0.641 \\
& Entre & & 0.421 \\
& Dentro & & 0.486 \\
\hline Despesas com Pessoal & Inteiro & 5.184 & 0.713 \\
& Entre & & 0.412 \\
& Dentro & & 0.585 \\
\hline Despesas com Investimento & Inteiro & 3.824 & 1.542 \\
& Entre & & 1.381 \\
& Dentro & & 0.644 \\
\hline
\end{tabular}

Fonte: Elaboração própria com dados da Secretaria do Tesouro Nacional.

Adicionalmente, devido ao corte temporal realizado nas análises de dados e as defasagens utilizadas para o ajuste do modelo, os parâmetros estimados nas variáveis de receita corrente captam mais precisamente variações longitudinais. Em outras palavras, os coeficientes obtidos apontam como as diferenças de receitas correntes per 
capita entre os municípios influenciam suas decisões de gastos. Os resultados destas elasticidades são consistentes com o modelo de Black (op. cit.) em que as arrecadações e os gastos tendem a ser selecionados mutuamente. Por sua vez, o parâmetro estimado de despesa defasada é consistente com a proposta de Hall (op. cit.), qual seja, o consumo no período passado tem influência no consumo do período corrente.

Nas Tabelas 3 e 4 são expostas as estimativas que identificam relações causais das receitas municipais com a despesa orçamentária, gastos com pessoal e com investimento para os municípios com população entre 50.000 e 300.000 habitantes e para aqueles com população inferior a 50.000 habitantes, respectivamente.

Os resultados das estimativas para os municípios de maior população, apresentados na Tabela 3, indicam que a melhor adequação é aquela em que não há defasagens nas variáveis de receitas. Os sinais obtidos nas estimativas sugerem uma relação positiva entre receitas correntes e despesas, como esperado.

A estimativa do modelo ( 1 ) indica que após a promulgação da LRF a despesa orçamentária aumenta $1,4 \%$ e 3,4\% quando há um acréscimo de $10 \%$ na receita tributária e na receita por transferência, respectivamente. Anterior à Lei, essa mesma relação era de $2 \%$ e $7 \%$.

As estimativas dos modelos (2) e (3), equações de despesas com pessoal e com investimento, apontam que a redução nas elasticidades da despesa orçamentária observadas no modelo (1) não tem relação direta com estas despesas. As estimativas apontam que a LRF não acarretou nenhuma mudança estrutural nos coeficientes das elasticidades calculadas de receitas.

Ressalte-se que as despesas com pessoal têm uma forte relação com a despesa por transferência. O aumento de $10 \%$ desta ocasiona um aumento de aproximadamente 9\% das despesas com pessoal. Por sua vez, a despesa com investimento, modelo (3), não apresentou relação estatística significante com as receitas correntes.

A Tabela 4 apresenta as equações de despesas dos municípios com população inferior a 50.000 habitantes. Os modelos estimados necessitaram de pelo menos quatro anos para que ocorressem os ajustes necessários nas variáveis. Além disso, como anteriormente, os sinais obtidos não são consistentes com a noção de que a LRF ocasionou uma redução acentuada na sensibilidade das despesas em relação às receitas correntes.

A estimativa do modelo (4), equação de despesa orçamentária, aponta que, após o vigor da LRF, houve um incremento da elasticidade despesa orçamentária/receita por 
transferência. Em média, o município que tem $10 \%$ a mais de receita por transferência elevou a despesa orçamentária aproximadamente em 7,3\%. O modelo (5) sugere que parte deste aumento esteve associado à despesa com pessoal. Antes da LRF, o modelo não identificou uma relação significante; no entanto, após a promulgação da LRF, o aumento de $10 \%$ da receita por transferência acrescentou à despesa com pessoal cerca de $3 \%$, e em menor valor em $0,7 \%$ quando a mesma variação ocorreu na receita tributária.

A estimativa do modelo (6) sugere que a despesa com investimento, mesmo antes da LRF, esteve positivamente associada com a receita tributária. Os resultados apontam que antes da LRF o acréscimo de $10 \%$ da receita tributária causava um aumento de $6,7 \%$ desta despesa. No entanto, após a promulgação da LRF esta relação diminuiu, passando para $5 \%$.

Embora contabilmente as despesas com investimento estejam associadas às despesas de capital, identificou-se uma possível vinculação entre despesa de capital e receita corrente de tributação. Como já discutido, isto pode ser feito quando o município realiza uma transferência do superávit do orçamento corrente para sua receita de capital. Em outras palavras, as estimativas sugerem que os municípios de população inferior a 50.000 habitantes, que respondem por 93\% dos municípios de Minas, têm associado receitas tributárias às despesas de investimento.

As estimativas não confirmam a hipótese de que os municípios mineiros tenham realizado uma associação direta entre aumento das despesas com pessoal e redução das despesas de investimento. Porém, à luz dos dados apresentados da Tabela 1, pode-se verificar que, ao contrário das receitas tributárias, as receitas de transferências foram fortemente ampliadas ao longo do período analisado, principalmente a partir do ano 2000.

Com efeito, os coeficientes estimados sugerem haver uma associação direta com as transferências realizadas por esferas de governo superiores. Portanto, os resultados obtidos esclarecem que o aumento das transferências, concomitante à implementação da LRF em 2000, acarretaram o crescimento das despesas com pessoal. Ao que parece, a LRF apenas intensificou este processo ao estabelecer textualmente que os municípios poderiam gastar até $60 \%$ de suas receitas com pessoal. Assim, de uma forma geral, para os presentes municípios analisados, nada se pode afirmar a respeito de uma possível substituição das despesas com investimentos, em razão do aumento dos gastos com pessoal, como poderiam sugerir os dados das Figuras 1 e 2, mas sim, uma aparente utilização do crescimento das receitas de transferências para gastos com pessoal. 
TABELA 3 - EQUAÇÃO DE GASTOS DOS MUNICÍPIOS MINEIROS COM POPULAÇÃO SUPERIOR 50.000 HABITANTES E INFERIOR $A$ 300.000 HABITANTES ( $T=11, N=57$ ), RESULTADOS DO PRIMEIRO PASSO DOS ESTIMADORES ARELLANO E BOVER

\begin{tabular}{|c|c|c|c|}
\hline Modelos & (1) & (2) & (3) \\
\hline Método & A e Bover & A e Bover & A e Bover \\
\hline Despesas & Orçamentária & Pessoal & Investimento \\
\hline Defasagens & $M=0$ & $M=0$ & $M=0$ \\
\hline \multirow[t]{2}{*}{$\operatorname{Des}_{i, t-1}$} & 0,031 & $0,221^{*}$ & $0,368^{\star \star *}$ \\
\hline & $(0,054)$ & $(0,127)$ & $(0,118)$ \\
\hline \multirow[t]{2}{*}{$R T r i_{i, t}$} & $0,211^{* * *}$ & 0,083 & 0,11 \\
\hline & $(0,029)$ & $(0,137)$ & $(0,149)$ \\
\hline \multirow[t]{2}{*}{ RTrans $_{i, t}$} & $0,724^{* \star *}$ & $0,898^{\star \star \star}$ & 0,322 \\
\hline & $(0,068)$ & $(0,222)$ & $(0,288)$ \\
\hline \multicolumn{4}{|c|}{ Variáveis Dummies - Lei de Responsabilidade Fiscal } \\
\hline \multirow[t]{2}{*}{$\operatorname{Des}_{i, t-1}$} & $0,316^{\star \star \star}$ & $-0,006$ & $-0,258^{\star \star}$ \\
\hline & $(0,102)$ & $(0,151)$ & $(0,126)$ \\
\hline \multirow[t]{2}{*}{$R T r i_{i, t}$} & $-0,073^{*}$ & $0,188^{*}$ & $-0,034$ \\
\hline & $(0,038)$ & $(0,103)$ & $(0,188)$ \\
\hline \multirow[t]{2}{*}{ RTrans $_{i, t}$} & $-0,383^{\star \star \star}$ & $-0,376$ & 0,093 \\
\hline & $(0,122)$ & $(0,31)$ & $(0,45)$ \\
\hline \multirow[t]{2}{*}{ Constante } & $0,847^{\star \star \star}$ & 1,275 & 0,135 \\
\hline & $(0,26)$ & $(1,004)$ & $(1,364)$ \\
\hline Graus de Liberdade & 167 & 87 & 167 \\
\hline$Q$ & 52,82 & 24,77 & 51,52 \\
\hline $\operatorname{Pr}>\chi^{2}$ & 1 & 1 & 1 \\
\hline Arellano e Bond & $-0,1424$ & $-0,0309$ & 0,6091 \\
\hline $\operatorname{Pr}>z$ & 0,8867 & 0,9753 & 0,5425 \\
\hline Observações & 514 & 373 & 514 \\
\hline
\end{tabular}

Notas: 1. Todos os modelos contêm variáveis dummies de tempo; 2. Erros padrão entre parênteses; 3. * significante a $10 \%{ }^{* *}$ significante a $5 \%$; $^{* *}$ significante a $1 \%$.

Fonte: Elaboração própria com dados da Secretaria do Tesouro Nacional. 
TABELA 4 - EQUAÇÃO DE GASTOS DOS MUNICÍPIOS MINEIROS COM POPULAÇÃO INFERIOR A 50.000 HABITANTES ( $T=11, N$ =790), RESULTADOS DO SEGUNDO PASSO DOS ESTIMADORES ARELLANO E BOVER E ARELLANO E BOND

\begin{tabular}{lccc}
\hline Modelos & $(4)$ & $(5)$ & $(6)$ \\
\hline Método & A e Bover & $A$ e Bond & $A$ e Bover \\
\hline Despesas & Orçamentária & Pessoal & Investimento \\
\hline Defasagens & $M=4$ & $M=4$ & $M=4$ \\
\hline Des $i_{i,-1}$ & $0,526^{* * *}$ & $0,284^{*}$ & $0,337^{* * *}$ \\
& $(0,139)$ & $(0,156)$ & $(0,082)$ \\
RTri $i_{i, t}$ & 0,046 & 0,016 & $0,670^{* *}$ \\
& $(0,057)$ & $(0,099)$ & $(0,317)$ \\
RTrans & $0,436^{* *}$ & $-0,53$ & 0,705 \\
& $(0,177)$ & $(0,371)$ & $(0,934)$ \\
\hline
\end{tabular}

\begin{tabular}{lccc}
\hline Variáveis Dummies - Lei de Responsabilidade Fiscal & & \\
\hline Des $s_{i,-1}$ & $-0,298^{\star *}$ & $-0,408^{* * *}$ & $-0,130$ \\
& $(0,133)$ & $(0,102)$ & $(0,086)$ \\
RTri $i_{i, t}$ & 0,032 & $0,068^{\star *}$ & $-0,168^{*}$ \\
& $(0,021)$ & $(0,032)$ & $(0,091)$ \\
RTrans $_{i, t}$ & $0,296^{\star *}$ & $0,310^{\star * *}$ & 0,201 \\
& $(0,134)$ & $(0,11)$ & $(0,240)$ \\
\hline Constante & 0,376 & 4,728 & $-1,251$ \\
& $(0,398)$ & $(3,418)$ & $(2,651)$ \\
\hline Graus de Liberdade & 59 & 41 & 59 \\
Q & 65,96 & 51,37 & 63,19 \\
Pr $>\chi^{2}$ & 0,2486 & 0,1286 & 0,3306 \\
\hline Arellano e Bond & 0,929 & $-0,4478$ & $-0,3614$ \\
Pr $>z$ & 0,3529 & 0,6543 & 0,7178 \\
\hline Observações & 3147 & 2461 & 3046 \\
\hline
\end{tabular}

Notas: 1. Todos os modelos contêm variáveis dummies de tempo; 2. Erros padrão entre parênteses; 3. * significante a $10 \%{ }^{* *}$ significante a $5 \%{ }^{* * *}$ significante a $1 \%$.

Fonte: Elaboração própria com dados da Secretaria do Tesouro Nacional

Neste âmbito, as estimativas confirmam a noção de que as despesas com pessoal têm forte dependência das receitas de transferências, mas, dado que parte das deci- 
sões de gastos realizados advém especificamente de programas determinados pelo governo federal, poder-se-ia argumentar que este aumento de gastos estaria sendo determinado pelo próprio governo central, e não um comportamento padronizado dos gestores municipais. No entanto, deve ser lembrado que o modelo com dados em painel utiliza a variável dummy de tempo para captar efeitos que ocorreram simultaneamente em todos os municípios em um dado período de tempo. A variável dummy de tempo controla efeitos simultâneos nos coeficientes estimados. Logo, estes apenas mostram quais são as fontes de receitas que mais influenciam as decisões de gastos e como elas têm influenciado as decisões de gastos nos períodos analisados. Portanto, é possível afirmar que, mediante o aumento das receitas por transferências, os municípios têm priorizado os gastos com pessoal.

Com efeito, observa-se que a LRF per se não foi a única responsável pelo abrupto crescimento das despesas com pessoal. $\mathrm{O}$ aumento das receitas por transferências exerceu papel fundamental neste processo de convergência identificado nos dados e nas estimativas, e a LRF sancionou esta possibilidade. O baixo crescimento dos gastos de investimentos, ao que parece, não está associado a uma substituição causada em consequência do aumento das despesas com pessoal. Como o aumento das receitas não tem refletido uma contrapartida nas despesas com investimento, $\mathrm{o}$ resultado, tal como vislumbrado na Figura 2, é a perda da participação das despesas com investimento em relação às receitas totais.

\section{CONCLUSÕES}

O presente trabalho realizou um estudo dos possíveis impactos da Lei de Responsabilidade Fiscal (LRF) no comportamento das despesas dos municípios de Minas Gerais. Para tanto, foram analisados cenários anteriores e posteriores da LRF, com base nos quais se comparou o comportamento das prefeituras municipais em relação às suas políticas de gastos. Inicialmente, foi identificada uma convergência da despesa com pessoal nos municípios mineiros, resultados estes já obtidos para os municípios brasileiros por Fiovarante et al. (op. cit.), Menezes (op. cit.) e Giuberti (op. cit.). Além disso, verificou-se também um processo de convergência do gasto com investimento.

A análise da LRF mostra que, originalmente, sua concepção não deveria conter dispositivos que determinassem níveis ótimos de gastos realizados nos municípios. O ponto básico da LRF é o de regulamentar a execução orçamentária para evitar abusos por parte de bases governistas quanto à utilização inapropriada de recursos públicos na administração local. Em outras palavras, o objetivo central da LRF é o 
controle dos gastos públicos na busca de uma administração mais transparente dos recursos.

No entanto, a junção de elementos pós ano 2000 desencadeou um processo de convergência de gastos com pessoal e austeridade das despesas de investimento em relação à receita total. Diante das análises anteriores, associadas às fundamentações que regem a Lei, é possível detectar três pontos básicos para estes fatos: (i) aumento das transferências das receitas correntes, (ii) restrição às operações de crédito, e (iii) processo de equalização dos gastos de pessoal pós-promulgação da LRF.

A conclusão desta sequência de fatos é que a LRF aumentou a dependência das receitas de transferências correntes. Ao sugerir explicitamente que os municípios poderiam aumentar seus gastos com pessoal até o limite de $60 \%$, a LRF levou os municípios a associarem diretamente aumento das transferências correntes com gastos de pessoal, além de reduzir o vínculo entre a despesa de investimento e a arrecadação tributária. Como a LRF obriga uma relação de equilíbrio entre receita e despesa orçamentária, associado ao fato de que as despesas com pessoal são de difícil corte, qualquer cenário em que haja uma redução das receitas por transferências deverá incidir sobre os gastos de investimento. Em outras palavras, em um ambiente de depressão macroeconômica, as rígidas regras e as severas punições previstas na LFR acabam limitando os gastos em investimentos públicos, pois essa é a área mais suscetível a cortes para que os limites fiscais sejam atingidos uma vez que os demais gastos apresentam uma estrutura mais rígida, sendo mais complicado alterá-los.

Ressalte-se, no entanto, que com relação aos resultados obtidos para os municípios com mais de 300.000 habitantes não há vinculação direta entre investimento e fonte de receitas, embora haja entre investimento e aumento das receitas totais e queda desta vinculação após a promulgação da LRF, bem como a fatia das receitas tributárias e de transferências direcionadas ao pagamento de pessoal. Não se pode associar, por seu turno, uma suposta vinculação entre eficiência e eficácia das políticas públicas após a lei, mesmo porque esta discussão não era o objetivo do trabalho.

\section{REFERENNCLAS}

AFONSO, J. R. R. Las relaciones intergubernamentales dentro de Brasil. Revista de la CEPAL, v. 84, p. 135-157, 2004.

ARELLANO, M.; BOND, S. Some tests of specification for panel data: Monte Carlo evidence and an application to employment equations. Review of Economic Studies, 58, p. 277-297, 1991. 
ARELLANO, M.; BOVER, O. Another look at the instrumental variable estimation of error-components models. Journal of Econometrics, 68, p. 29- 51, 1995.

BARRO, R. On the determination of public debt. Journal of Political Economy, v. 87, n. 5 , p. $940-971,1979$.

BLACK, D. The theory of committees and elections. Cambridge: Cambridge University Press, 1958.

BLUNDELL, R.; BOND, S. Initial conditions and moment restrictions in dynamic panel data models. Journal of Econometrics, 87, p. 115-143, 1997.

DAHLBERG, M.; JOHANSSON E. An examination of the dynamic behaviour of local governments using GMM Bootstrapping methods. Journal of Applied Econometrics, 15, p. 401-416, 2000.

FIORAVANTE, D. G.; PINHEIRO, M. M. S.; VIEIRA, R. S. V.; SANTOS, J. C. Lei de responsabilidade fiscal e finanças públicas municipais: impactos sobre despesas com pessoal e endividamento. IPEA, 2006. (Texto para Discussão, n. 1223).

FRIEDMAN, M. The limitations of tax limitation. Policy Review, v.5, n.78, p. 7-14, 1978.

GIUBERTI, A. C. Lei de responsabilidade fiscal: efeitos sobre o gasto com pessoal dos municípios brasileiros. Anais do XXXIII ANPEC, 2005.

GREENE, W. H. Econometric Analisys. 5ª ed. Prentice Hall, 2003.

HALL, R. Stochastic implications of the life cycle-permanent income hypothesis: theory and evidence. Journal of Political Economy, v. 86, n. 6, p. 971-987, 1978.

HOLTZ-EAKIN, D.; NEWEY, W.; ROSEN, H. Estimating vector autoregressions with panel data. Econometrica, v. 56, p. 1371-1395, 1988.

MENEZES, R. T. Impactos da lei de responsabilidade fiscal sobre os componentes de despesa dos municípios brasileiros. Brasília: ESAF, 2005. 64 p. Monografia premiada em $1^{\circ}$ lugar no X Prêmio Tesouro Nacional - 2005, Lei de Responsabilidade Fiscal, Brasília (DF).

NISKANEN, W. Bureaucracy and representative government. Chicago: Aldine-Atherton, 1971.

PEACOCK, A.; WISEMAN, J. Approaches to the analysis of government expenditures growth. Public Finance Quarterly, v. 7, n. 1, p. 3-23, 1979.

TAVARES, M. A. R.; MANOEL, A.; AFONSO, J. R. Uma proposta para um novo regime fiscal no Brasil: o da responsabilidade fiscal. 1999. Disponível em: <www. joserobertoafonso.ecn.br>. Acesso em: 29 dez. 2004.

TAYLOR, L. Reconstructing macroeconomics. Cambridge, Massachussets: Harvard University Press, 2004. 
WACHTER, S.; TZAVALIS, E. Detection of structural breaks in linear dynamic panel data models. Queen Mary, University of London, Department of Economics, 2004. (Working Paper 505).

WRAY, R. Understanding modern money. Cheltenham, UK: Edward Elgar, 1998. 